\title{
An effective improvement for enhancing the strength and feasibility of FRP spike anchors
}

\author{
Wei Sun ${ }^{\mathrm{a}, \mathrm{b}}$, Shukui Liu ${ }^{\mathrm{c}}$, Chunyang Zhang ${ }^{\mathrm{a}}$ \\ ${ }^{a}$ Key Laboratory of Ministry of Education for Mechanics on Western Disaster and Environment, \\ School of Civil Engineering and Mechanics, Lanzhou University, Lanzhou 730000, China \\ ${ }^{b}$ School of Engineering, University of Southampton, Southampton, SO17 1BJ, UK \\ ${ }^{c}$ School of Mechanics and Civil Engineering, China University of Mining and Technology, 221116, \\ China
}

\begin{abstract}
Spike anchors are promising remedies to prevent the debonding failure of FRP sheets. The performance of anchored FRP sheets largely depends on critical parameters such as the extending bond length of FRP sheet over the embedded spike and bend radius, greatly limiting their efficiency and feasibility in field. Moreover, their long-term performance dealing with possible bond loss is still unknown. Recently, an anchorage system consisting of a spike anchor and two patches has been developed. This anchorage system was expected to have several advantages over conventional spike anchors, which were rarely explored but are presented in this paper. A total of 21 experiments have been conducted to demonstrate their merits in terms of higher anchor strengths and minimizing the impacts of the extending bond length over the embedded spike, bend radius and FRP-concrete bond. Experimental results also suggest a great remedy to further improve the anchor efficiency by reducing the fanning angle. Thus, the proposed system could be considered as an efficient and feasible anchorage for FRP sheets.
\end{abstract}

Keywords: Spike anchor; Anchorage system; Bond length; Bend radius; FRP-concrete bond; Fanning angle 


\section{Introduction}

Light, strong and non-corrosion FRP composites [1-4] offer a quick method for externally strengthening concrete structures. However, a premature FRP debonding from concrete substrate greatly compromises the high-strength merit of FRP material [5]. Various anchors have been therefore developed to make fuller use of externally bonded (EB) FRP sheets by preventing the premature debonding failure. Metal anchors consisting of bolts and plates are able to effectively delay EB FRP debonding from concrete substrate [6,7]. Nevertheless, the external application of metal anchors might need a specific anti-corrosion treatment. Notable stresses concentrated in the vicinity of metal-FRP connections could also compromise their applications in field. In order to address those issues, anchorages tend to be made by the same FRP material as that is used for EB FRP sheets, i.e. FRP anchors.

FRP strips with the fiber oriented perpendicular to the tensile direction were applied to delay the debonding process of EB FRP sheets [8]. However, this method might not be highly effective unless the strip was notably prestressed. A promising remedy could be wrapping EB FRP sheets with U-shape FRP strips [9-11]. Although U-wrapping anchors were able to prevent the premature debonding failure, they inherently required notably more FRP material to make the anchors and more surface preparation for installing the anchors on the sides of concrete elements. Meanwhile, FRP spike anchors have been gaining more and more attention because of their high-efficiency, easy-installation and small-size merits. As shown in Fig.1 (a), FRP spike anchors are installed by embedding one end into concrete elements and fanning out the other end bonded on the EB FRP sheet $[12,13]$. While the EB FRP sheet starts debonding from concrete substrate, the spike anchor is able to provide an alternative load-transferring mechanism for preventing the debonding failure. Current investigations suggest that key parameters, e.g. embedment depth $\left(h_{e}\right)$, bend radius $\left(R_{b}\right)$ and embedded angle $\left(\alpha_{e}\right)$ (see Fig. 1 (b)) determines both the capacity and 
failure mode of anchored EB FRP sheets [14]. In order to prevent an anchorage system being pulled off, the minimum embedment depth was recommended to be at least $100 \mathrm{~mm}$ or 4 inch [15]. A 13-mm-radius bend was suggested to prevent spike anchors being prematurely cut off [16]. Embedded angle can be used to determine the stress state [17]. Existing studies also demonstrate the impact of anchor strength and hole diameter $\left(d_{h}\right)$ on the behavior of anchored EB FRP sheets [14,18]. An adequate strength ratio of FRP anchor to EB FRP sheet $\left(S_{\text {ratio }}\right)$ is suggested to be no less than 2 by previous studies [5]. The hole diameters are determined by the diameter of anchor dowel $\left(d_{a}\right)$. The diameter ratio of hole to anchor dowel is expected to be greater than 1.5 and no more than 2.2 [16]. Moreover, EB FRP sheets are recommended to be extended over the anchor dowel. As shown in Fig. 1 (b), the distance from anchor dowel to the corresponding end of EB FRP sheet $\left(l_{\text {end }}\right)$ should be more than $225 \mathrm{~mm}$ to realize the nominal anchor strength [19]. This might suggest feasible issues in the usage of spike anchors to shear strengthen reinforced concrete elements with a limited depth. Another limitation of current spike anchors could be short of a ready method to control the bend radius $\left(R_{b}\right)$ in field. The real radius might therefore vary from case to case, suggesting a possibly overestimated anchor strength obtained from a nominal bend radius. In order to make a fuller usage of EB FRP material, the fanning angle $\alpha_{f}$ (see Fig. 1 (c)) is also expected to be properly adjusted so that the entire width of EB sheets can be fully covered by the fanned out anchor [16]. Recently, a FRP anchorage system consisting of a spike anchor and two FRP patches have been developed to improve the reliability of conventional FRP spike anchors $[5,16,20,21]$. It was also found that this anchorage system could make fuller use of EB FRP sheet than conventional spike anchors did [21]. In this study, three-point bending tests have been conducted to demonstrate the merits of the anchorage 
performance of the anchorage system for partially unbonded FRP sheets has also been studied. Those

partially unbonded tests were conducted to simulate possible bond loss between two anchorage systems under the natural impact of UV light and heat [22,23]. Compared with fully bonded tests, capacity loss was observed from those partially unbonded tests. This observation provides with valuable data for evaluating the durability of the anchored EB FRP system. Moreover, the study has explored a possible method (i.e. adjusting the fanning angle) to further improve the anchorage system.

\section{Current design recommendations on spike anchors}

$$
f_{f b}=\left(0.07 r_{b}+0.45\right) f_{f u}
$$

$$
f_{f b}=\left(0.05 r_{b}+0.3\right) f_{f u}
$$

in which

$$
f_{f b}=\left(0.3 h_{e} / 150+0.5 r_{b} \alpha_{e} / 90^{0}\right) f_{f u}
$$

$$
f_{f b}=f_{f u}\left[\left(0.06 r_{b}+0.21\right)+0.22 S_{\text {ratio }}^{-1.15}+0.23\left(\alpha_{e} / 90^{0}-1\right)\right]
$$



conventional spike anchors, which could be greatly improved by using the proposed anchorage system consisting of FRP anchors and patches.

\section{Experiments}

As shown in Fig. 2, three-point flexural tests have been conducted to determine the strength of anchored EB FRP sheets installed on the tensile surface of test specimens (see Fig. 3 (a)-(b)). Specimens were concrete blocks with a constant dimension of $152 \times 152 \times 610 \mathrm{~mm}^{3}$ as shown in Fig. 3 (b)-(c). Two separated U-shape FRP strip were applied on the sides of specimens to prevent concrete shear failure. A $25 \mathrm{~mm}$ cut was made at the midspan to control the cracking path. The test setup and specimens were developed exclusively for isolating anchor behavior [16]. More details can be found in literature [16].

Tyfo sch-11 up [28] was used to fabricate EB FRP sheets with a dimension of $127 \times 482 \mathrm{~mm}^{2}$ and FRP anchorage systems. The FRP strength ratio of anchor to sheet at any section was a constant value of 2.0. Direct tensile tests in accordance with ASTM D3039 were conducted on five $15 \times 240 \mathrm{~mm}^{2}$ FRP coupons with $15 \times 40 \mathrm{~mm}^{2}$ FRP end-tabs. The average values of modulus $E_{f}$ and ultimate strain $\varepsilon_{f}$ were 95.7 $\mathrm{GPa}$ and 0.011 , respectively. The manufacturer-specified values (e.g. laminate thickness $=0.51 \mathrm{~mm}$, tensile modulus $=95.8 \mathrm{GPa}$ and ultimate strain=0.01) stemmed from more experimental results were very close to measured values, and will be applied in the following studies. According to Chinese code GB 50010, the average concrete strength obtained from five cubic specimens with a dimension of $150 \times 150 \times 150 \mathrm{~mm}^{3}$ was $36 \mathrm{MPa}$ (or $28 \mathrm{MPa}$ for cylinder strength).

In the group consisting of specimen No. 1-9 (see Table 1), all tests have identical FRP systems expect for the patch arrangement. Conventional spikes with no patches (NP) have been applied for the first three specimens, i.e. No. 1-3 in Table 1. Then, transverse patches (TP) have been used for another three 
specimens (No. 4-6) to improve the load transferring mechanism within a short $l_{\text {end }}$ of $38 \mathrm{~mm}$. For specimen No. 7-9, both transverse and longitudinal patches (TLP) have been applied to achieve further improvements. Those patches had a constant dimension of $127 \times 127 \mathrm{~mm}^{2}$. All spike anchors were inserted into pre-drilled holes with a bend radius of $13 \mathrm{~mm}$ (R13), then fanned $49^{\circ}$ (F49) to fully cover the EB FRP sheet. The group consisting of specimen No. 10-15 was applied to demonstrate the impact of bend radius and bond loss on the anchorage system with both transverse and longitudinal patches. All specimens had a fanning angle of $49^{\circ}$ in this group in which specimen No. 10-12 have a 0 mm bend $127 \times 228 \mathrm{~mm}^{2}$ unbonded area while two-patch regions with an area of $127 \times 127 \mathrm{~mm}^{2}$ were well bonded on concrete substrate as shown in Fig. 3 (a). Specimen No. 16-21 were tested to demonstrate the impact of reducing fanning angle (from $49^{\circ}$ to $37^{\circ}$ ) on various radius scenarios (R0 and R13) and bond conditions. The bend radius of specimen No. 16-18 and specimen No. 19-21 are $0 \mathrm{~mm}$ (R0) and $13 \mathrm{~mm}$ (R13), respectively. Moreover, the bond condition of specimen No. 16-18 and specimen No. 19-21 are well bonded and partially unbonded, respectively. As listed in Table 1, the nomenclature used for identifying experiments are bond condition (i.e. B and U stands for bonded and partially unbonded)patch arrangement (i.e. NP for no patch, TP for transverse patch or TLP for transverse + longitudinal patch)-bend radius (i.e. R13 or R0)-fanning angle (i.e. F49 or F37)-experiment ID (a, b, and c).

Applied loads were recorded by the load cell of the testing machine CSS-WAW1000DL. Deflections were the relative displacements between the midspan and two supports. A camera system (DO3THINK U3S1250M-H) was used to measure those displacements. Fig. 4 shows that the predicted ultimate load $P_{u}$ obtained from the nominal ultimate force of the EB FRP sheet at midspan $F_{u f}$ by using the following expressions with $w_{s}=$ specimen width, mm, $c=$ depth of neutral axis, mm, $A_{f}=$ section area of the FRP 
sheet, $\mathrm{mm}^{2}, \varepsilon_{c}=$ the ultimate compressive strain of concrete, $f_{c}^{\prime}=$ specified compressive stress of concrete, $\mathrm{MPa},\left(f_{c u}=f_{c}^{\prime} / 0.78\right)$ :

Force and moment equilibrium were applied to obtain the two unknowns $\left(P_{u}\right.$ and $\left.c\right)$. The span from the applied load to the support $\left(L_{p s}\right)$ was $267 \mathrm{~mm}$. The relative FRP height (i.e. $\left.h_{f}\right)$ was $152 \mathrm{~mm}$. The compression force $F_{u c}$ and the corresponding moment $M_{u c}$ were obtained from integrating the concrete stress $f_{c}$ at the compressive region. The concrete stress is given as follows [29]:

$$
f_{c}=f_{c}^{\prime}\left(2 \varepsilon_{c} / \varepsilon_{0}-\left(\varepsilon_{c} / \varepsilon_{0}\right)^{2}\right)
$$

\section{Results and discussion}

A total of 21 experiments have been conducted to demonstrate the merits of the anchorage system in terms of minimizing the impact of $l_{e n d}, r_{b}$ and bond condition. Those improvements are presented and discussed in this section. The section also explores a feasible remedy to further improve the anchorage system. 
The results of three experiments (No. 1-3) using conventional spike anchors are presented in this section. They served as control tests to demonstrate the performance of selected equations and the improvements achieved by the anchorage system. Fig. 5 (a) shows the load-deflection curves of the three experiments. All curves clearly suggest two distinctive stages. Firstly, increasing the applied load results in slightly increased deflections, producing stiff linear responses. Notably deflections were gradually 
In this section, patches have been applied to improve the performance of the spike anchor having a short $l_{\text {end }}$ (i.e. $l_{\text {end }}=38 \mathrm{~mm}$ ). Transverse-patches were first applied for three experiments (No. 4-6) to mitigate the anchor delamination. Then, an upgraded system, i.e. the two-patch system, has been used for another three experiments (No. 7-9). All FRP details are identical in experiment No. 1-9 expect for patch arrangements (see Table 1).

As shown in Fig. 6 (a), all transverse-patch experiments (No. 4-6) develop two-stage loading curves similar to that of the comparable experiments using conventional spike anchors (No. 1-3). Two out of three specimens failed in ultimate loads which were unable to fracture the EB FRP sheets as shown in Fig. 6 (a). Moreover, all experiments failed in anchor-sheet delamination. This suggests that the transverse-patch arrangement cannot fully develop the tensile strength of FRP sheets. Nevertheless, transverse-patch experiments achieve notably larger loads than that of the comparable experiments (No. 1-3) as listed in Table 2, demonstrating their improvements. The slight torsion end (see Fig. 6 (b)) might suggest an uneven fiber distribution in the fanning region, resulting in an uneven force distribution and then producing the delamination between the anchor and the sheet.

In order to prevent the delamination failure, two patches consisting of both transverse and longitudinal patches have been applied in experiment No. 7-9. The introduction of longitudinal patches aim to minimize the impact of unevenly fanning out fibers. Moreover, longitudinal patches are able to increase the tensile stiffness in the anchor region, limiting the relative FRP-concrete slip $[5,20]$. The anchor region might therefore remain completely bonded on concrete substrate until the ultimate failure. The remaining bond would help to transfer the tensile force, increasing the apparent strength of the anchorage system. Transverse patches were then applied to minimize the impact of angled fibers due to fanning out, further 
smoothing the force-transferring mechanism and preventing the anchor-sheet delamination and anchor rupture. Therefore, the application of the two-patch system was expected to achieve 1) a higher apparent capacity by keeping the anchored region well bonded until the ultimate failure, and 2) delivering a better force-transferring mechanism to prevent anchor-sheet delamination and anchor rupture. As listed in Table 2 and Fig. 7 (a), all two-patch experiments developed notably ultimate loads that were able to fracture the FRP sheet. Their improvements were even much more notably by comparing their strengths with the corresponding strengths of conventional spikes and transverse-patch applications as shown in Fig. 7 (b). Possible variations of loading condition, installation quality and specimen material produced diverse failure modes. One experiment fractures the FRP sheet at $83 \mathrm{kN}$, and the rest ruptures the anchors at $82 \mathrm{kN}$ and $91 \mathrm{kN}$, respectively. The typical failures of sheet fracture and anchor rupture are shown in Fig. 7 (c). Those observations suggest that the two-patch anchorage system is able to prevent the failure of anchor delamination, and to more efficiently transfer the tensile force even within a short $l_{\text {end }}$ (i.e.

\subsection{Impact of $\boldsymbol{R}_{\boldsymbol{b}}$ and bond condition on the anchorage system}

This section explores the impacts of bend radius and bond loss on the two-patch anchorage system with a short $l_{\text {end }}=38 \mathrm{~mm}$. The introduction of the proposed anchorage system was expected to achieve a higher reliability by minimizing the impact of those two parameters. Three experiments (No. 10-12) have been conducted to simulate the worst scenario in which the two-patch anchorage system deals with a sharp corner, i.e. $R_{b}=0 \mathrm{~mm}$. Another three experiments (No. 13-15) are conducted to demonstrate the 
performance of the anchored EB FRP sheet with no FRP-concrete bond (or bond loss) in the region between two adjacent patches. Then, anti-delamination measures could be more efficiently and effectively applied. All details are the same in experiments (No. 7-15) except for bend radius and bond condition.

Even dealing with a sharp corner $\left(R_{b}=0 \mathrm{~mm}\right)$, the two-patch anchorage system developed adequate 

on the failure mode and the strength of the anchored EB FRP sheet. $\mathrm{mm}$ and possible strength loss because of bond condition. In order to minimize the impact of those two critical factors, remedies can be made to prevent the delamination failure, and further improve the anchor efficiency.

\subsection{Impact of fanning angle}

Fanning angle was considered to have limited impact on the anchor strength as long as specimens failed in sheet fracture [5]. In this study, several experiments failed in either anchor delamination or anchor rupture suggesting a demand for improving the two-patch anchorage system. Reducing the fanning angle, suggesting a stiffer anchored region. This stiffer region would help to limit the anchor- 

of three partially unbonded specimens failed in sheet fracture, developing comparable ultimate loads to that of corresponding tests (No. 7-9 see Fig. 11 (b)) with a well bond condition. The rest one failed because concrete cover peeled off as shown in Fig. 11 (c). Without an adequate bond condition, the tensile force was primarily distributed by a small region of concrete around the anchor, resulting in stress concentration and concrete failure. This failure mode was not effectively prevented by reducing the fanning angle from $49^{\circ}$ to $37^{\circ}$. In short, reducing the fanning angle was able to improve the load transferring from the sheet to the anchor, preventing the anchor delamination and anchor rupture. Nevertheless, the reduced angle might not be able to prevent the failure of concrete peel off.

1. Compared with conventional spike anchors, the anchorage system tends to make fuller use of FRP

3. The bond condition between the anchorage system and FRP sheet can be improved by narrowing 
unfavorable failure of anchor-sheet delamination and anchor rupture. 


\section{Acknowledgments}

The support of the National Natural Science Foundation of China [grant numbers 51608244 and 51608520], Natural Science Foundation of Jiangsu Province (BK20160265), China Postdoctoral Science Foundation (2016M590516), the Key Laboratory of Ministry of Education for Mechanics on Western are greatly appreciated. 


\section{References}

[1] Lou T, Karavasilis TL. Time-dependent assessment and deflection prediction of prestressed concrete beams with unbonded CFRP tendons. Compos Struct 2018;194:365-76. doi:10.1016/j.compstruct.2018.04.013.

[2] Lou T, Min D, Sun W, Chen B. Numerical assessment of continuous prestressed NSC and HSC members with external CFRP tendons. Compos Struct 2020;234:111671. doi:10.1016/j.compstruct.2019.111671.

[3] Lou T, Peng C, Karavasilis TL, Min D, Sun W. Moment redistribution versus neutral axis depth in continuous PSC beams with external CFRP tendons. Eng Struct 2019;209:109927. doi:10.1016/j.engstruct.2019.109927.

[4] Jiang SF, Ma SL, Wu ZQ. Experimental study and theoretical analysis on slender concrete-filled CFRP-PVC tubular columns. Constr Build Mater 2014. doi:10.1016/j.conbuildmat.2013.11.089.

[5] Sun W, Jirsa JO, Ghannoum WM. Behavior of anchored carbon fiber-reinforced polymer strips used for strengthening concrete structures. ACI Mater J 2016. doi:10.14359/51688637.

[6] Wu Y, Huang Y. Hybrid Bonding of FRP to Reinforced Concrete Structures. J Compos Constr 2008;12:266-73. doi:10.1061/(ASCE)1090-0268(2008)12:3(266).

[7] Dat Duthinh and Monica Starnes. Strengthening of Reinforced Concrete Beams with Carbon FRP. Compos Constr 2001;1:493-8.

[8] Kalfat R, Al-Mahaidi R. A prediction model for bidirectional fiber patch anchors used to enhance the performance of FRP materials bonded to concrete. Compos Struct 2014;117:51-8. doi:10.1016/j.compstruct.2014.05.034.

[9] Pham HB, Al-Mahaidi R. Prediction Models for Debonding Failure Loads of Carbon Fiber Reinforced Polymer Retrofitted Reinforced Concrete Beams. J Compos Constr 2006;10:48-59. doi:10.1061/(ASCE)1090-0268(2006)10:1(48).

[10] Al-Amery R, Al-Mahaidi R. Coupled flexural-shear retrofitting of RC beams using CFRP straps. Compos Struct 2006;75:457-64. doi:10.1016/j.compstruct.2006.04.037.

[11] Smith ST, Teng JG. Shear-Bending Interaction in Debonding Failures of FRP-Plated RC Beams. Adv Struct Eng 2003;6:183-99. doi:10.1260/136943303322419214.

[12] Niemitz CW, James R, Breña SF. Experimental Behavior of Carbon Fiber-Reinforced Polymer (CFRP) Sheets Attached to Concrete Surfaces Using CFRP Anchors. J Compos Constr 2010;14:185-94. doi:10.1061/(ASCE)CC.1943-5614.0000064.

[13] Orton SL, Jirsa JO, Bayrak O. Design Considerations of Carbon Fiber Anchors. J Compos Constr 2008;12:608-16.

[14] Villanueva Llauradó P, Ibell T, Fernández Gómez J, González Ramos FJ. Pull-out and shearstrength models for FRP spike anchors. Compos Part B Eng 2017. doi:10.1016/j.compositesb.2017.02.029.

[15] Kim. Use of CFRP to provide continuity in existing reinforced concrete members subjected to extreme loads. 2008.

[16] Sun W. Development of a testing methodology for the design and quality control of carbon fiber reinforced polymer (CFRP) anchors. Constr Build Mater 2018;164:150-63. doi:10.1016/j.conbuildmat.2017.12.192.

[17] Ozbakkaloglu T, Saatcioglu M. Tensile Behavior of FRP Anchors in Concrete. J Compos Constr 2009;13:82-92. doi:10.1061/(asce)1090-0268(2009)13:2(82). 
[18] Kim SJ, Smith ST. Pullout Strength Models for FRP Anchors in Uncracked Concrete. J Compos Constr 2010;14:406-14. doi:10.1061/(asce)cc.1943-5614.0000097.

[19] Zhang HW, Smith ST. Influence of FRP anchor fan configuration and dowel angle on anchoring FRP plates. Compos Part B Eng 2012. doi:10.1016/j.compositesb.2011.11.072.

[20] Sun W, Ghannoum WM. Modeling of anchored CFRP strips bonded to concrete. Constr Build Mater 2015;85:144-56. doi:10.1016/j.conbuildmat.2015.03.096.

[21] Sun W, Liu H, Wang Y, He T. Impacts of configurations on the strength of FRP anchors. Compos Struct 2018;194:126-35. doi:10.1016/j.compstruct.2018.04.020.

[22] Zhai Z, Feng L, Li G, Liu Z, Chang X. The anti-ultraviolet light ( UV ) aging property of aluminium particles / epoxy composite. Prog Org Coatings 2016;101:305-8.

[23] Sun W, Liu H, He T. Development of a novel FRP composite with high-strength, largedeformation and tensile-behavior designable properties: Design concept and experimental program. Compos Part B Eng 2019;167:448-60. doi:10.1016/j.compositesb.2019.03.016.

[24] Japan Society of Civil Engineers (JSCE). Recommendation for design and con- struction of concrete structures using continuous fiber reinforcing materials. Concrete engineering series 23. Tokyo 1997; 1997.

[25] ACI committee 440. Guide for the design and construction of externally bonded FRP systems for strengthening existing structures. 1996.

[26] Lee C, Ko M, Lee Y. Bend strength of complete closed-type carbon fiber-reinforced polymer stirrups with rectangular section. J Compos Constr 2014. doi:10.1061/(ASCE)CC.19435614.0000428 .

[27] Shehata E, Morphy R, Rizkalla S. Fibre reinforced polymer shear reinforcement for concrete members: Behaviour and design guidelines. Can J Civ Eng 2000. doi:10.1139/100-004.

[28] Fyfe Co.LLC. Tyfo ${ }^{\circledR}$ SCH-11UP Composite, 2015.

[29] Wight JK, McCormac J. Reinforced Concrete: Mechanics and Design. Pearson; 2015. doi:10.1680/mobe.34525.0615.

[30] Sun W, Peng X, Liu H, Qi H. Numerical studies on the entire debonding propagation process of FRP strips externally bonded to the concrete substrate. Constr Build Mater 2017;149:218-35. doi:10.1016/j.conbuildmat.2017.05.117.

[31] Sun W, Peng X, Yu Y. Development of a simplified bond model used for simulating FRP strips bonded to concrete. Compos Struct 2017;171:462-72. doi:10.1016/j.compstruct.2017.03.066.

[32] del Rey Castillo E, Griffith M, Ingham J. Straight FRP anchors exhibiting fiber rupture failure mode. Compos Struct 2019;207:612-24. doi:10.1016/j.compstruct.2018.09.073.

[33] del Rey Castillo E, Dizhur D, Griffith M, Ingham J. Experimental testing and design model for bent FRP anchors exhibiting fiber rupture failure mode. Compos Struct 2019;210:618-27. doi:10.1016/j.compstruct.2018.11.091. 


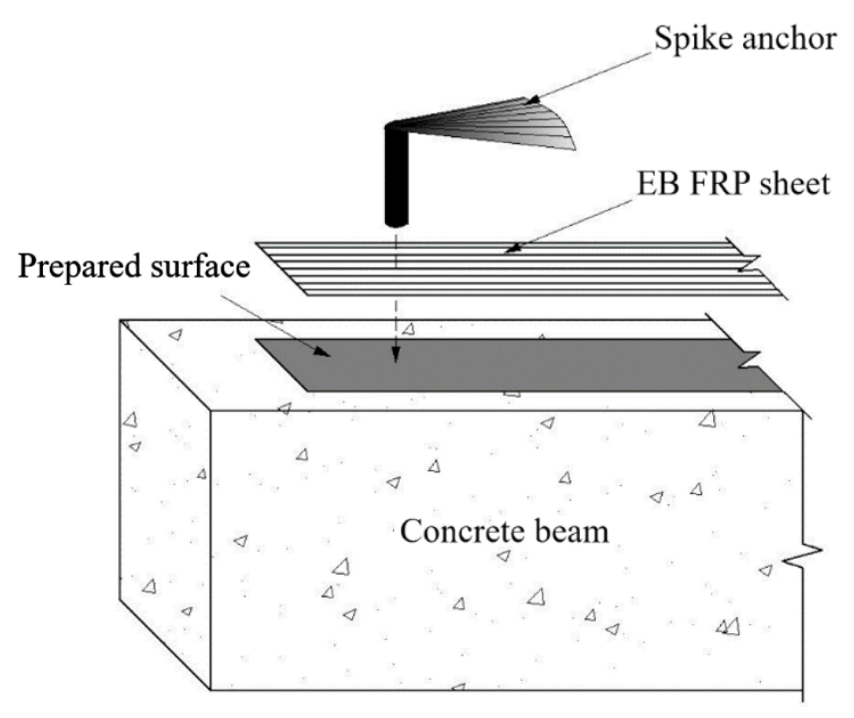

(a) Installing a typical FRP spike anchor

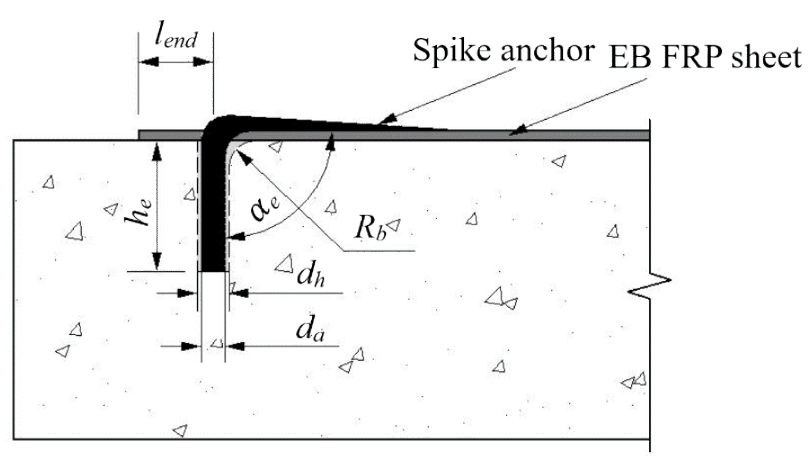

(b) Anchor details

EB FRP sheet

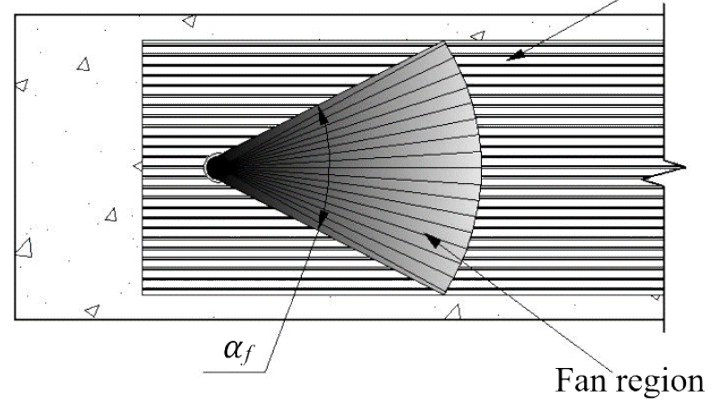

(c) A FRP spike anchor bonded onto FRP sheet

Fig.1. A typical FRP spike anchor 


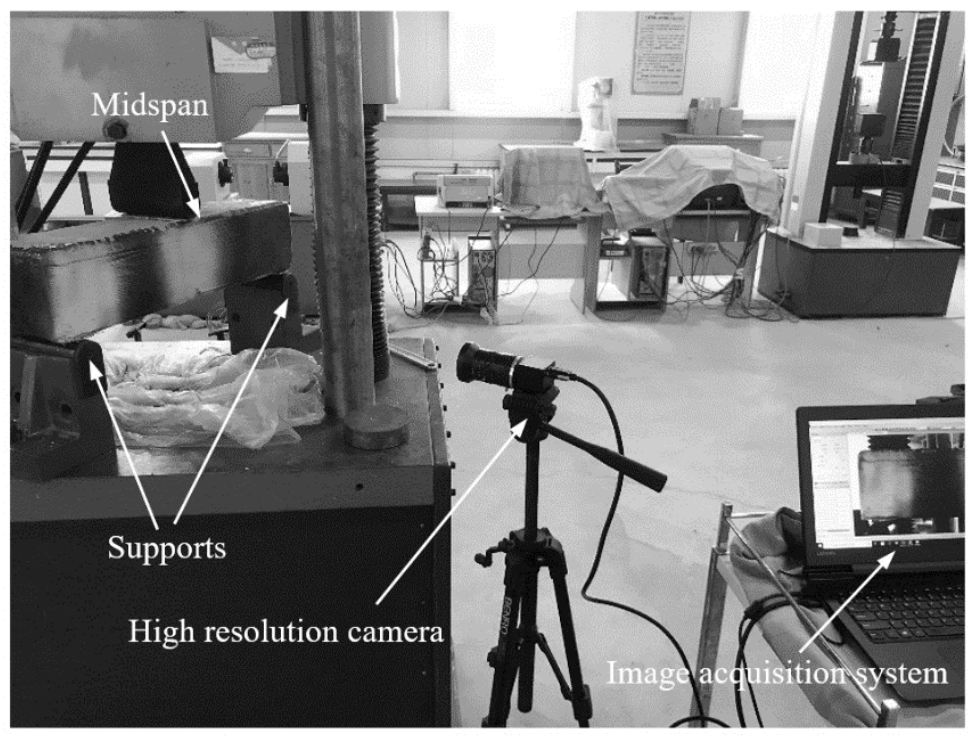

Fig.2. Three-point flexural test setup 


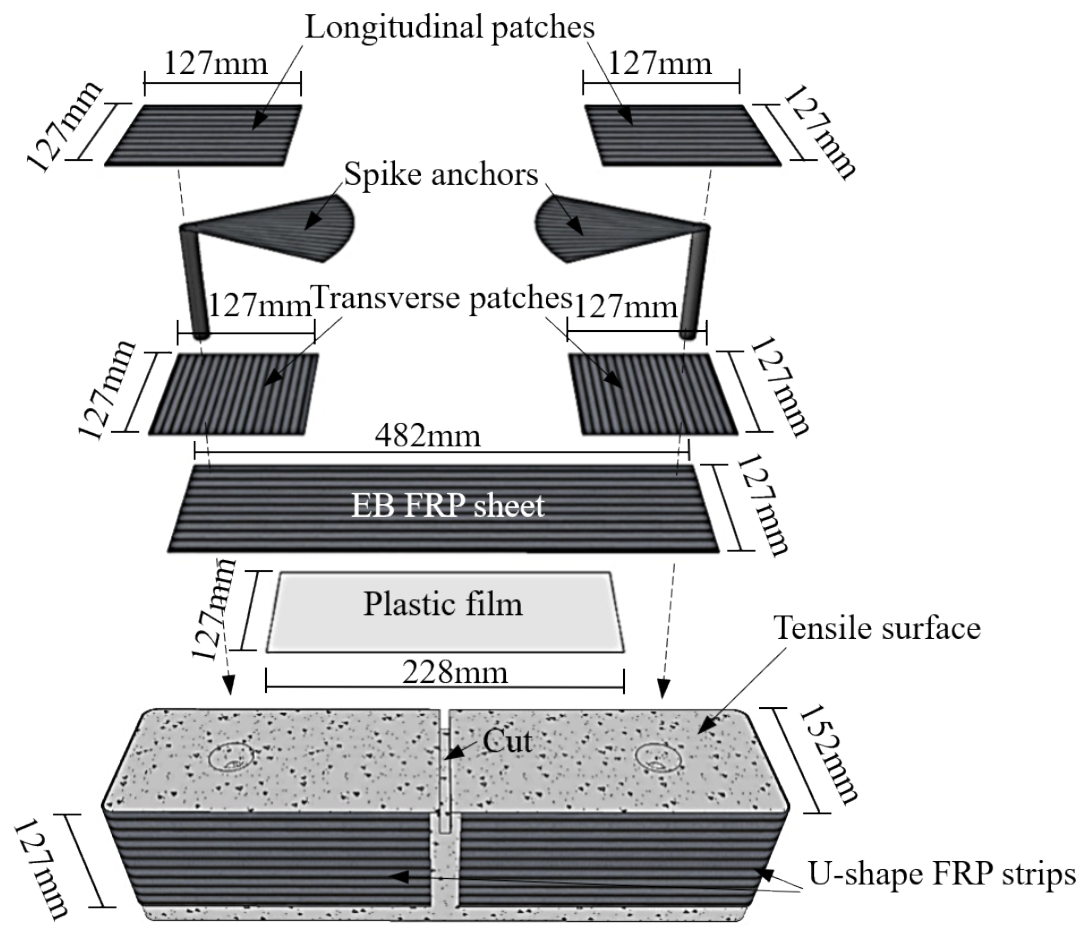

(a) FRP details

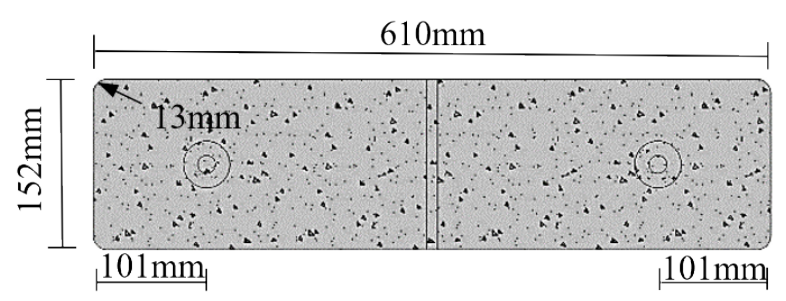

(b) Tensile surface of concrete specimen

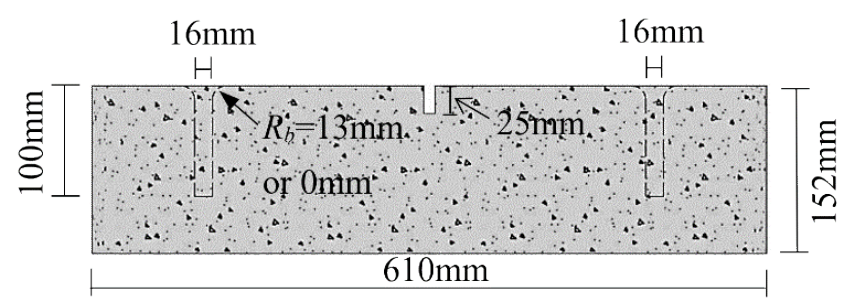

(c) Side view of concrete specimen

Fig.3. Test specimens 

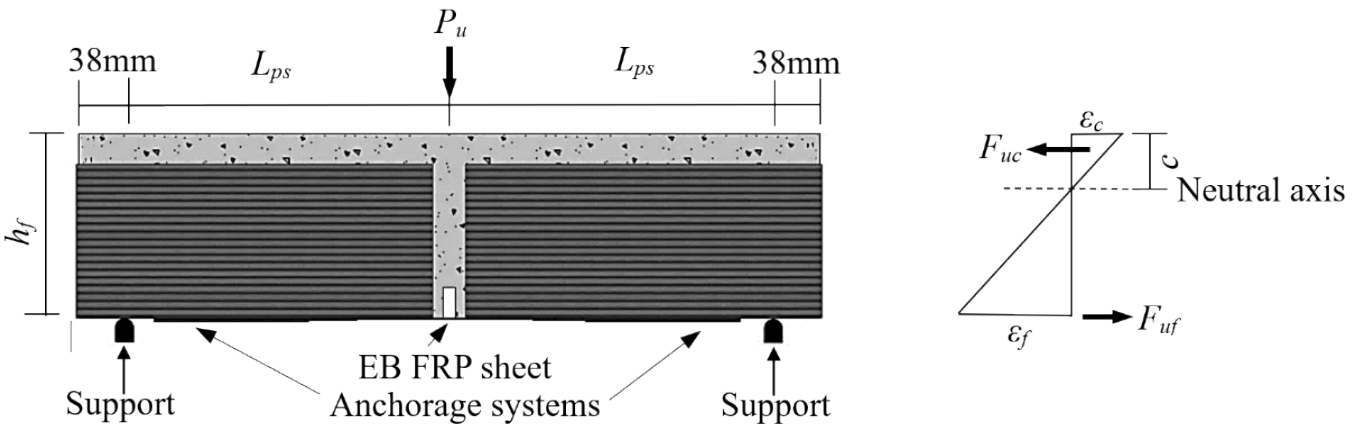

Fig.4. Beam equilibrium 


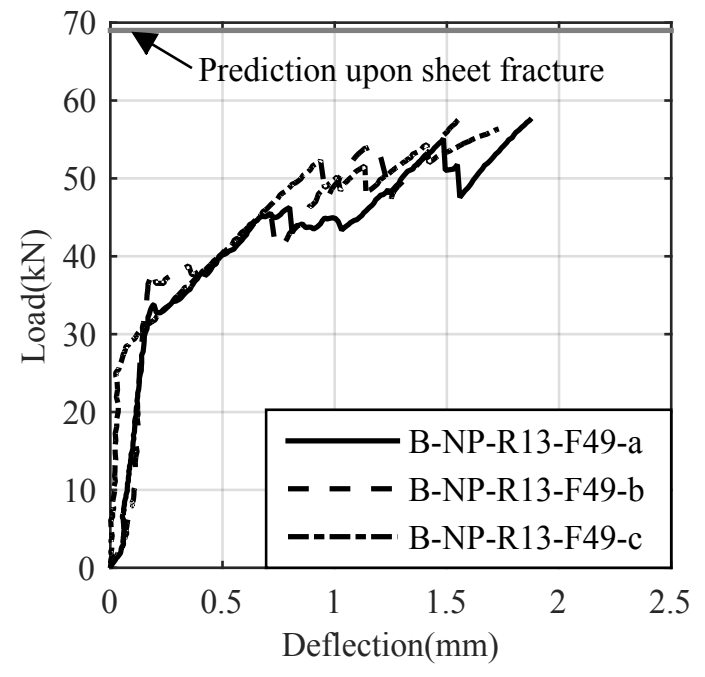

(a) Load-deflection curves

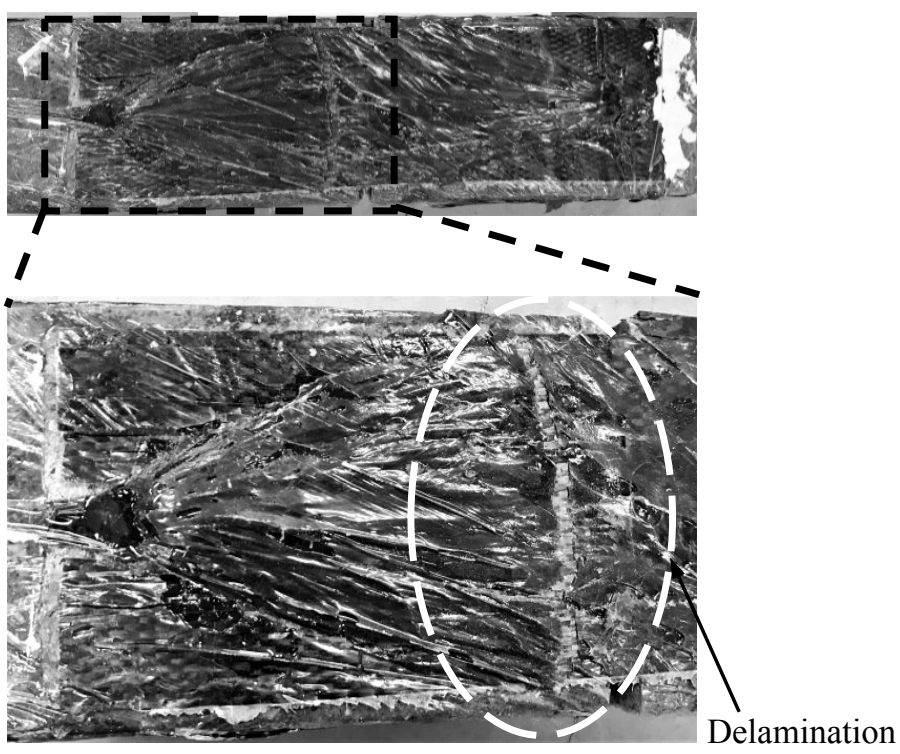

(b) Failure modes

Fig.5. Experimental results of specimens with no patches 


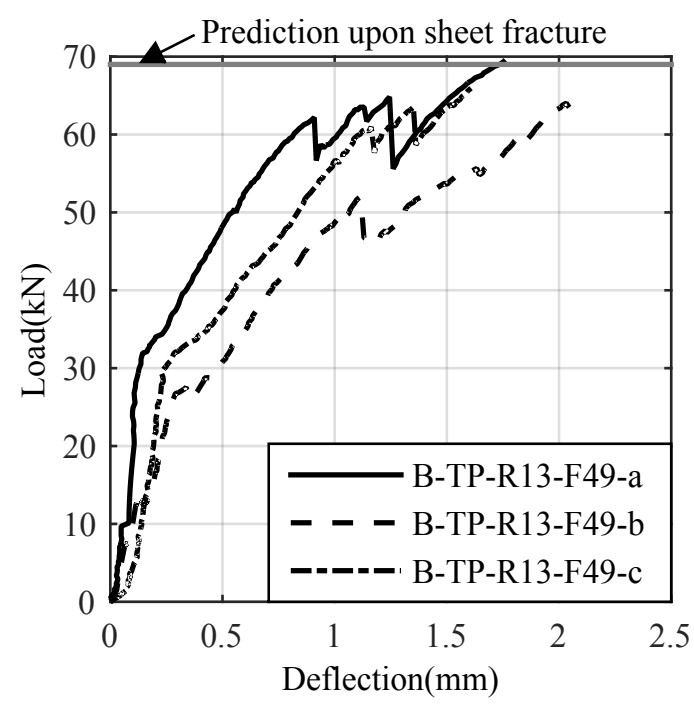

(a) Load-deflection curves

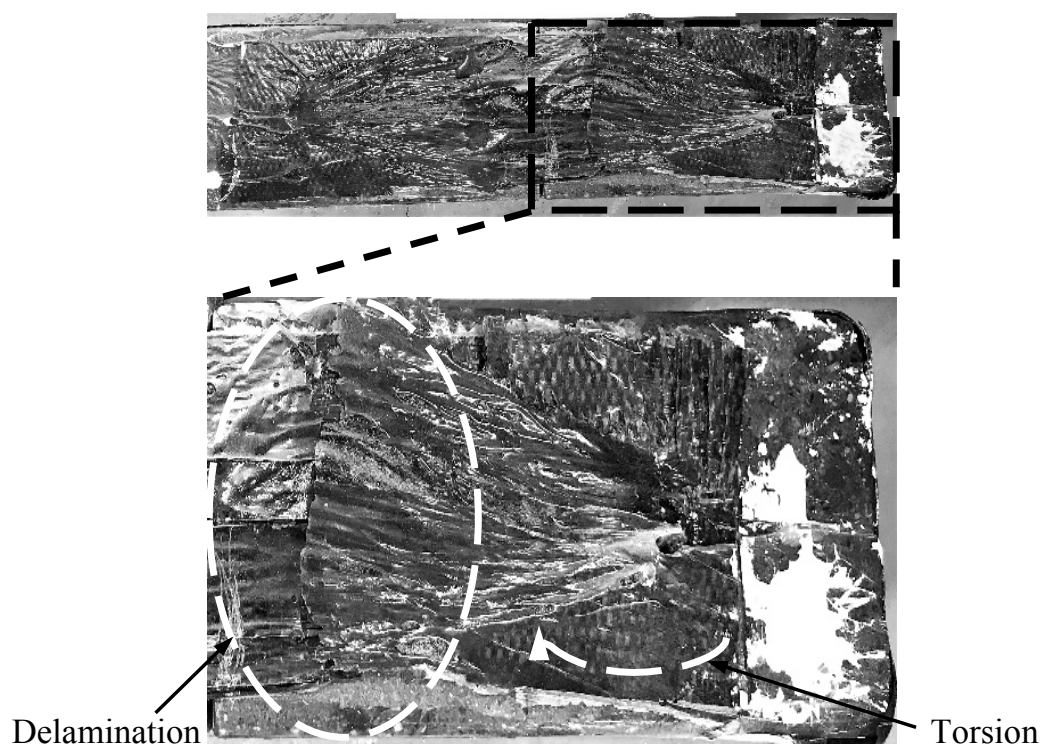

(b) Failure modes

Fig.6. Experimental results of specimens with transverse patches 


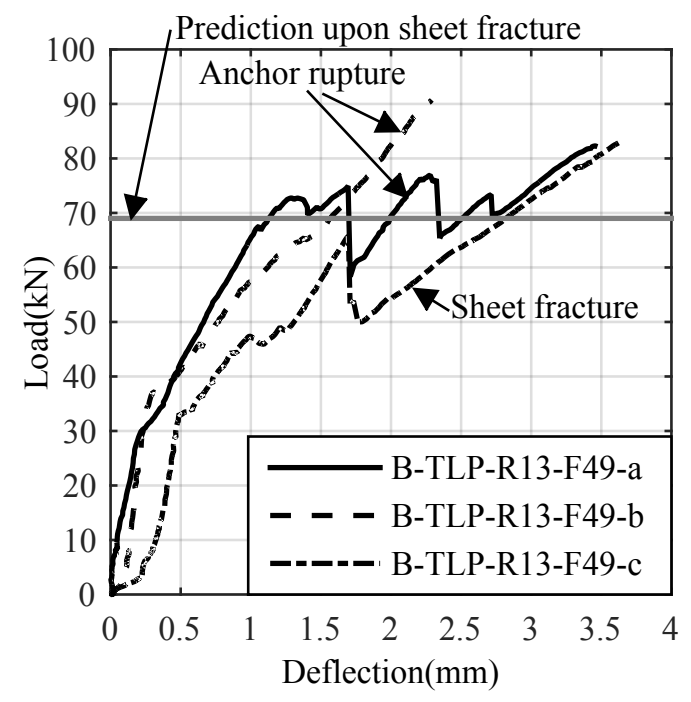

(a) Load-deflection curves

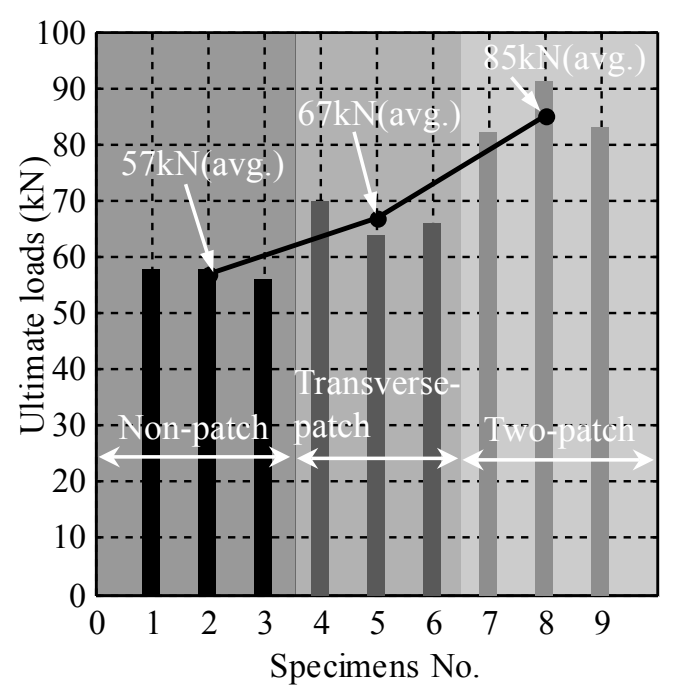

(b) Comparions of non-patch, transverse-patch, and two-patch applications
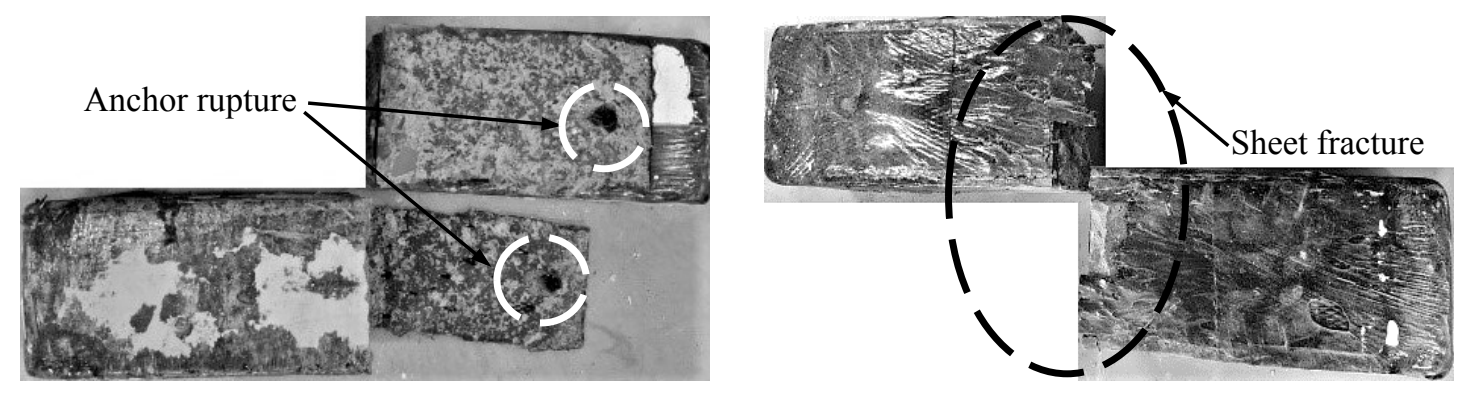

(c) Failure modes

Fig.7. Experimental results of specimens with two patches 

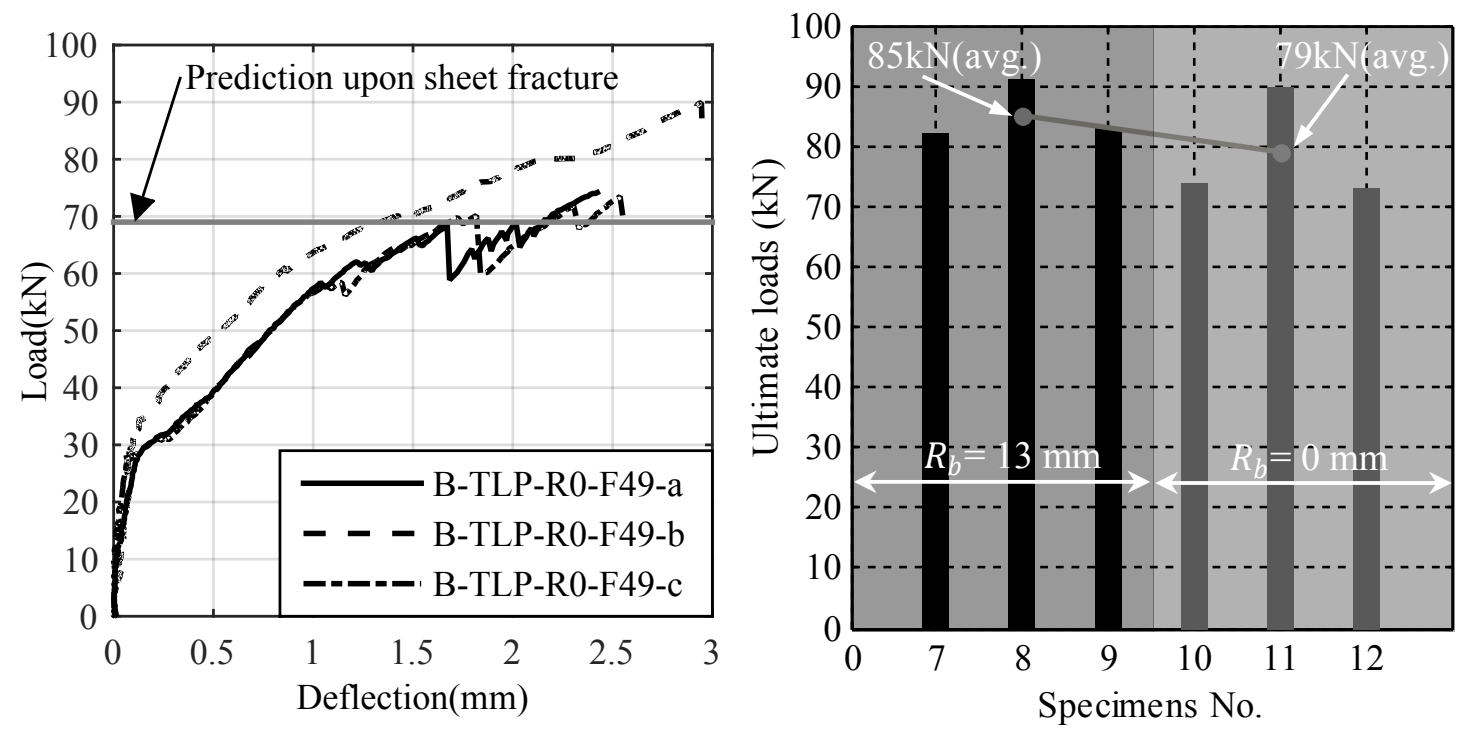

(a) Load-deflection curves

(b) Comparisons between $R_{b}=13 \mathrm{~mm}$ and $R_{b}=0 \mathrm{~mm}$

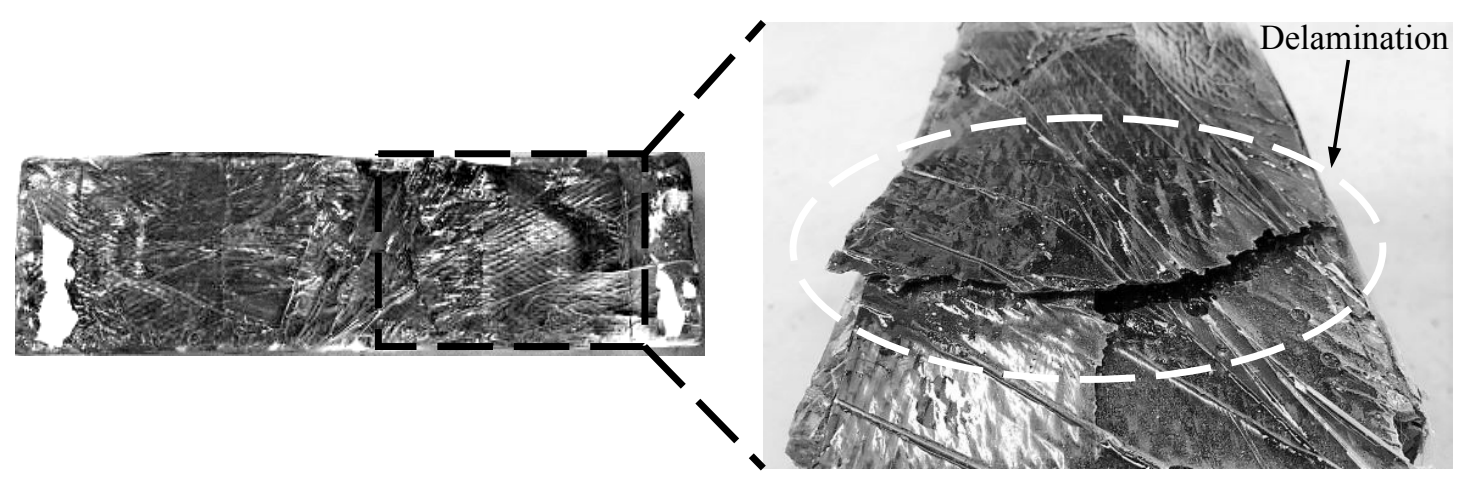

(c) Failure modes

Fig.8. Experimental results of two-patch specimens with a bend radius of $0 \mathrm{~mm}$ 


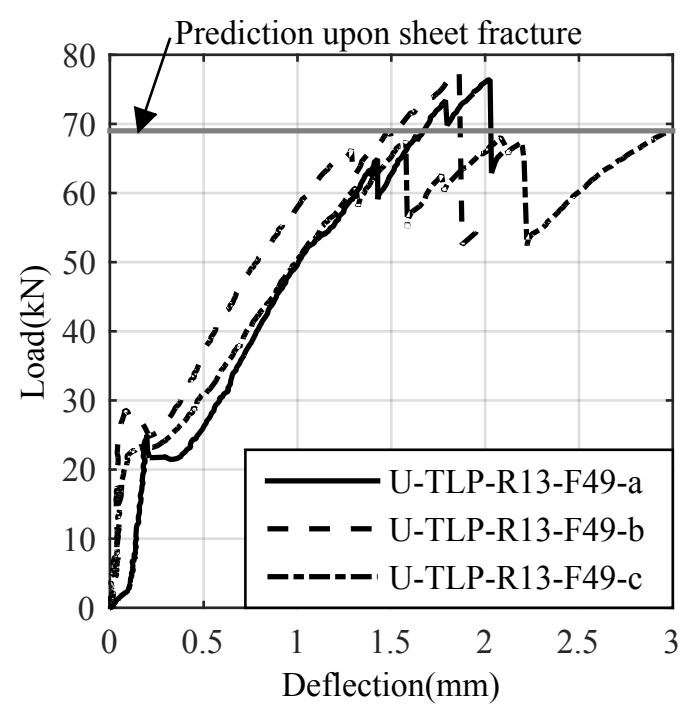

(a) Load-deflection curves

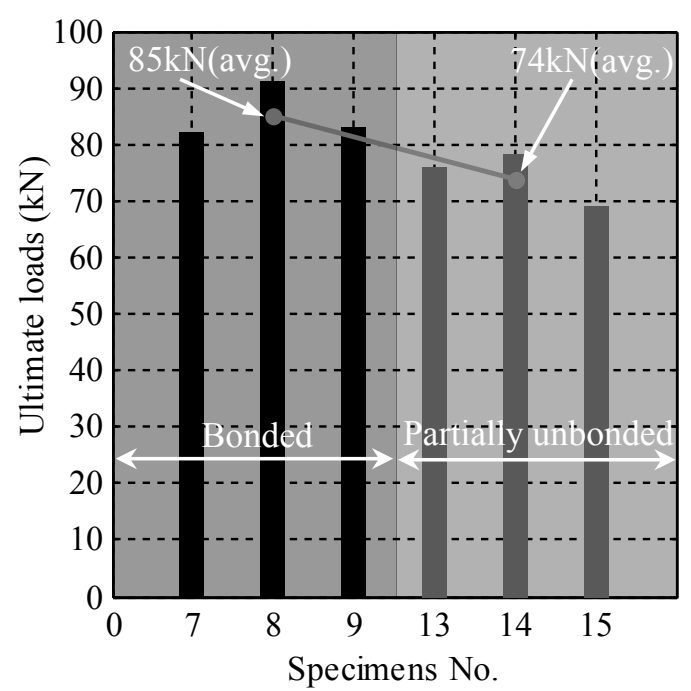

(b) Comparison between bonded and partially unbonded applications

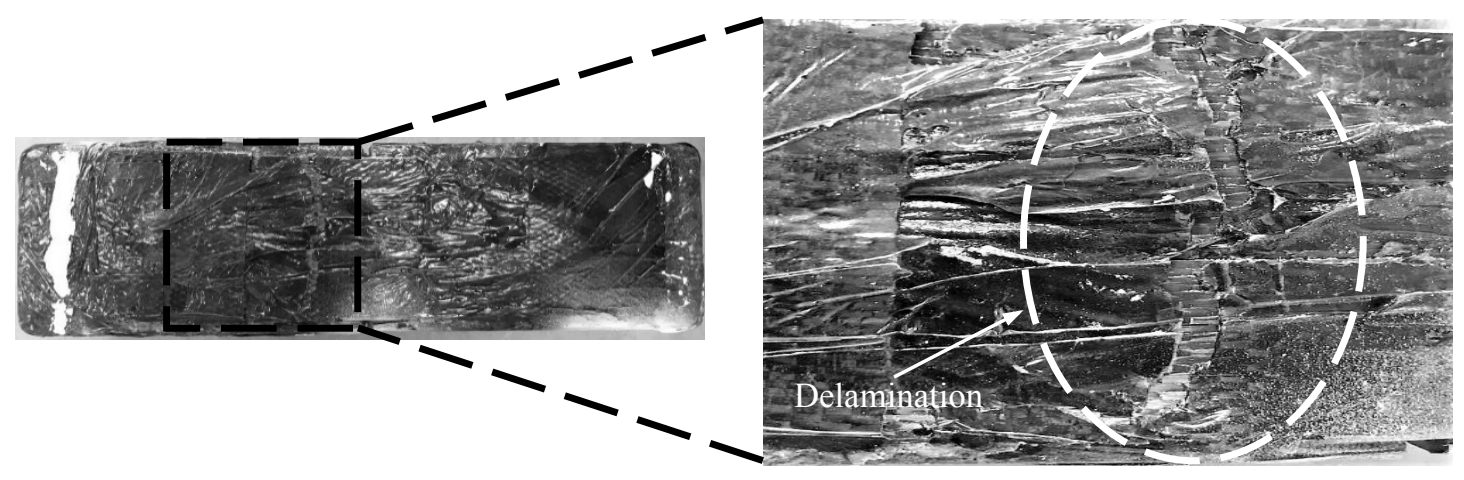

(c) Failure modes

Fig.9. Experimental results of partially unbonded specimens with two patches 


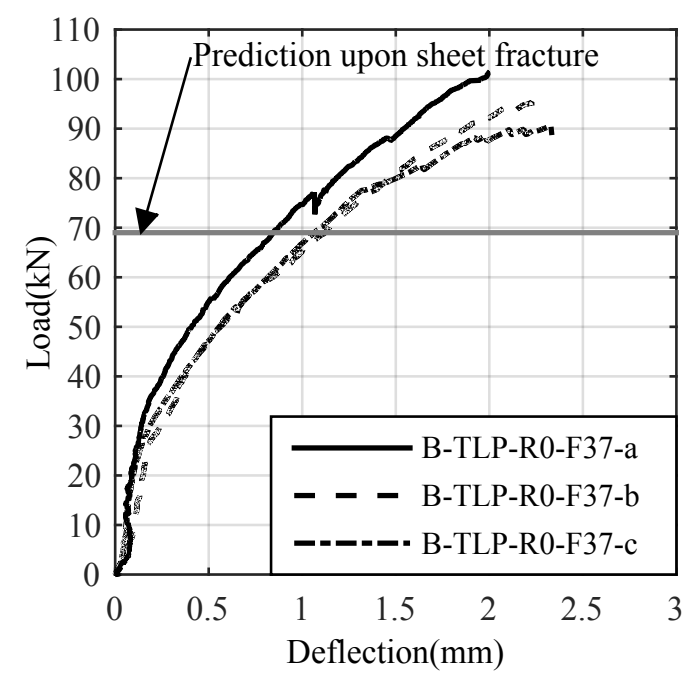

(a) Load-deflection curves

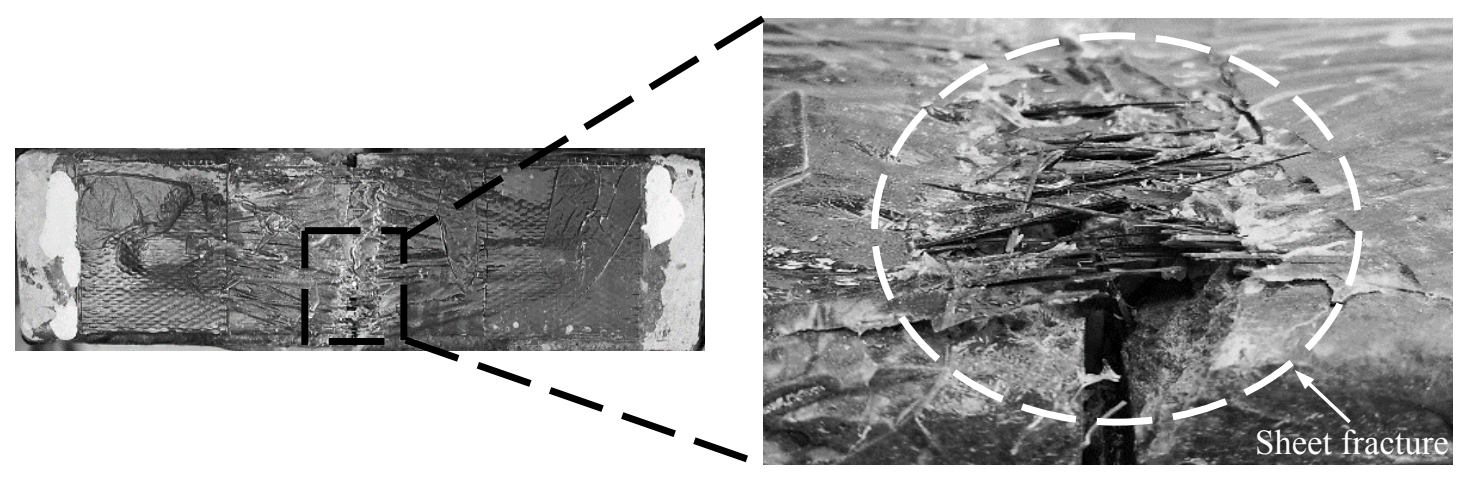

(b) Failure modes

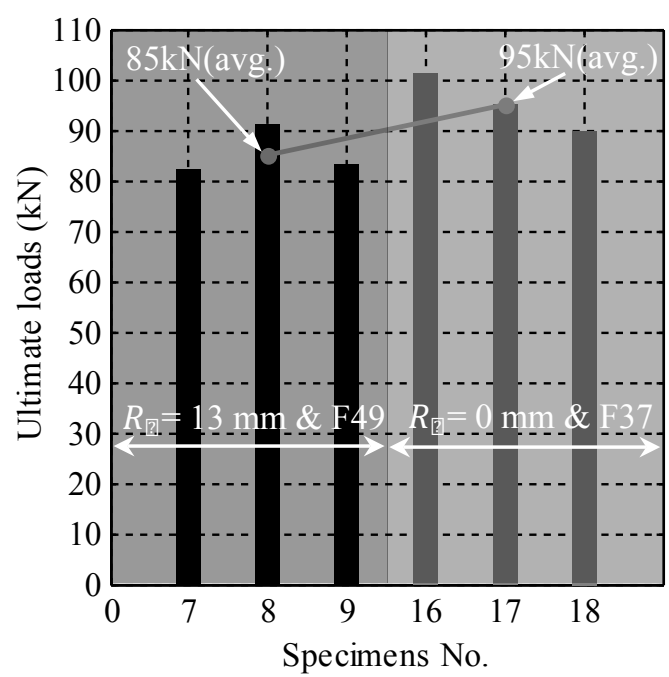

(c) Comparison between $R_{b}=13 \mathrm{~mm} \& \mathrm{~F} 49$ and $R_{b}=0 \mathrm{~mm} \& \mathrm{~F} 37$

Fig.10. Experimental results of specimens with a bend radius of $0 \mathrm{~mm}$ and fanning angle of $37^{\circ}$ 


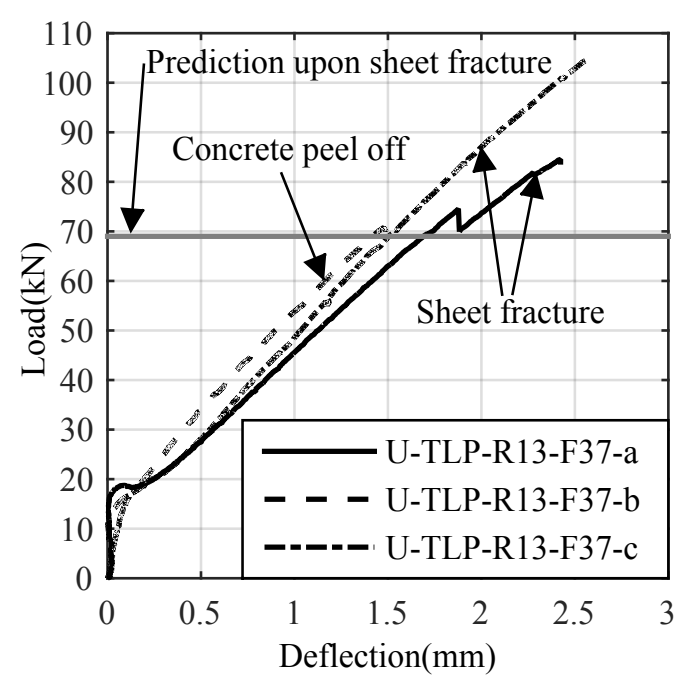

(a) Load-deflection curves

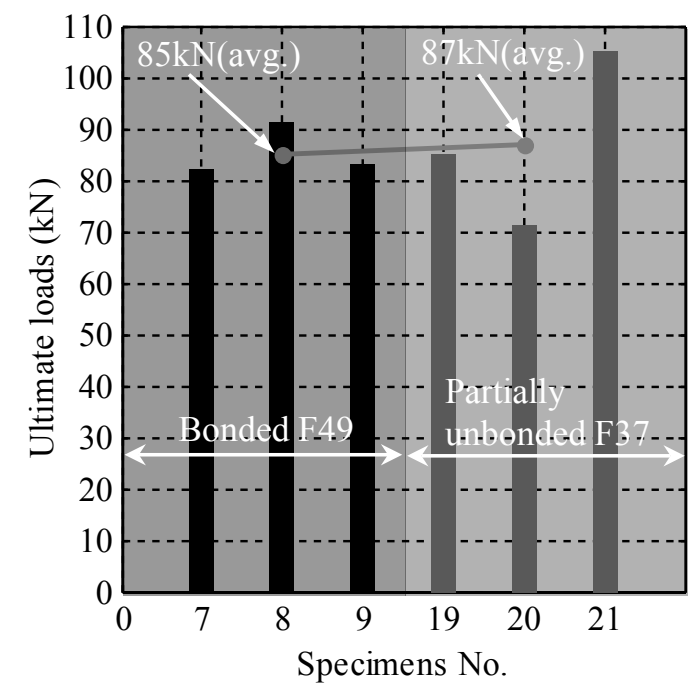

(b) Comparisons between bonded F49 and partially unbonded F37 applications

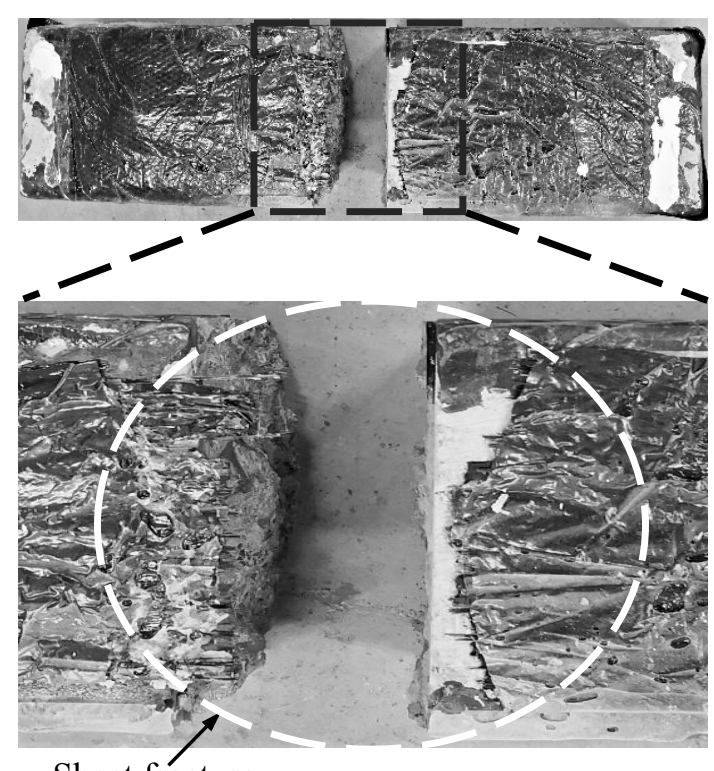

Sheet fracture
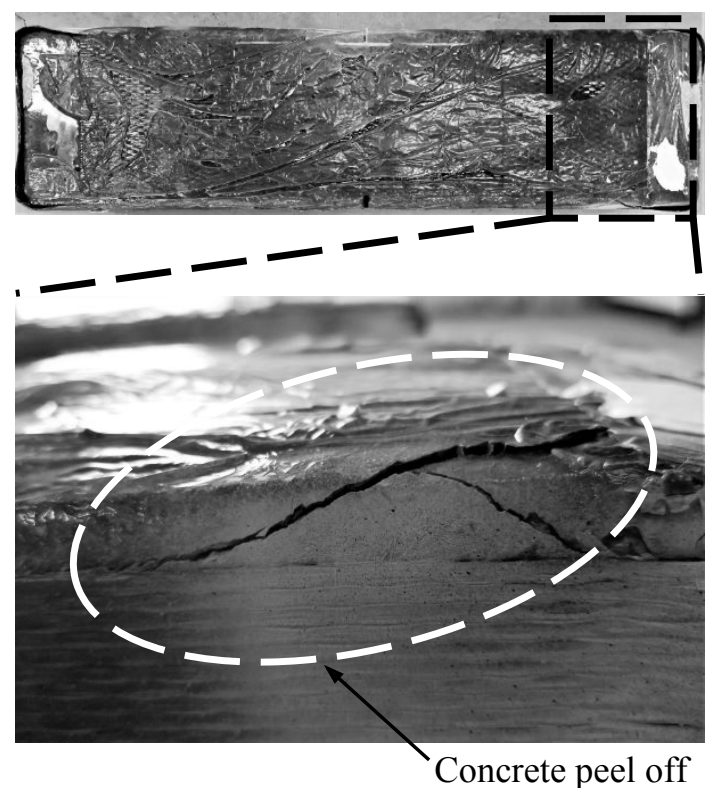

(c) Failure modes

Fig.11. Experimental results of partically unbonded specimens with fanning angle of $37^{\circ}$ 
Table 1. Specimen details

\begin{tabular}{|c|c|c|c|c|c|c|c|c|}
\hline \multirow[b]{2}{*}{ No. } & \multirow[b]{2}{*}{$\begin{array}{c}\text { Specimen } \\
\text { ID }\end{array}$} & \multirow[b]{2}{*}{$\begin{array}{c}\text { Bond } \\
\text { condition }\end{array}$} & \multicolumn{2}{|c|}{ Patch details } & \multirow{2}{*}{$\begin{array}{l}\text { Bend } \\
\text { radius } \\
(\mathrm{mm})\end{array}$} & \multicolumn{3}{|c|}{ Fan details } \\
\hline & & & $\begin{array}{c}\text { Transverse } \\
\text { Patches } \\
\left(\mathrm{mm}^{2}\right)\end{array}$ & $\begin{array}{c}\text { Longitudinal } \\
\text { Patches } \\
\left(\mathrm{mm}^{2}\right)\end{array}$ & & $\begin{array}{c}\text { Angle } \\
\left(^{\circ}\right)\end{array}$ & $\begin{array}{c}\text { Length } \\
(\mathrm{mm})\end{array}$ & $\begin{array}{l}\text { Area } \\
\left(\mathrm{mm}^{2}\right)\end{array}$ \\
\hline $1-3$ & B-NP-R13-F49 & Bonded & ---- & ---- & 13 & 49 & 153 & 10021 \\
\hline $4-6$ & B-TP-R13-F49 & Bonded & $127 \times 127$ & ----- & 13 & 49 & 153 & 10021 \\
\hline $7-9$ & B-TLP-R13-F49 & Bonded & $127 \times 127$ & $127 \times 127$ & 13 & 49 & 153 & 10021 \\
\hline $10-12$ & B-TLP-R0-F49 & Bonded & $127 \times 127$ & $127 \times 127$ & 0 & 49 & 153 & 10021 \\
\hline $13-15$ & U-TLP-R13-F49 & $\begin{array}{l}\text { Partially } \\
\text { Unbonded }\end{array}$ & $127 \times 127$ & $127 \times 127$ & 13 & 49 & 153 & 10021 \\
\hline $16-18$ & B-TLP-R0-F37 & Bonded & $127 \times 127$ & $127 \times 127$ & 0 & 37 & 200 & 12931 \\
\hline $19-21$ & U-TLP-R13-F37 & $\begin{array}{l}\text { Partially } \\
\text { Unbonded }\end{array}$ & $127 \times 127$ & $127 \times 127$ & 13 & 37 & 200 & 12931 \\
\hline
\end{tabular}


Table 2. Experimental results

\begin{tabular}{|c|c|c|c|c|c|c|c|c|c|}
\hline No. & Specimens & $\begin{array}{c}\text { Ultimate } \\
\text { loads } \\
(\mathrm{kN})\end{array}$ & $\begin{array}{c}\text { Averages } \\
\text { of } \\
\text { ultimate } \\
\text { loads } \\
(\mathrm{kN})\end{array}$ & $\begin{array}{c}\text { Eq.(1) } \\
\text { resulted } \\
\text { in } f_{f b} / \\
P_{u} \\
(\mathrm{MPa} / \\
\mathrm{kN})\end{array}$ & $\begin{array}{c}\text { Eq.(2) } \\
\text { resulted } \\
\text { in } f_{f b} / \\
P_{u} \\
(\mathrm{MPa} / \\
\mathrm{kN})\end{array}$ & $\begin{array}{c}\text { Eq.(4) } \\
\text { resulted } \\
\text { in } f_{f b} / \\
P_{u} \\
(\mathrm{MPa} / \\
\mathrm{kN})\end{array}$ & $\begin{array}{c}\text { Eq. }(5) \\
\text { resulted } \\
\text { in } f_{f b} / \\
P_{u} \\
(\mathrm{MPa} / \\
\mathrm{kN})\end{array}$ & $\begin{array}{l}\text { Measured } \\
\qquad P_{u} \\
\text { resulted } \\
\text { in } f_{f b} \\
(\mathrm{MPa})\end{array}$ & Failure modes \\
\hline 1 & B-NP-R13-F49-a & 58 & & $514 / 72$ & $346 / 49$ & $247 / 35$ & $365 / 51$ & 413 & Delamination \\
\hline 2 & B-NP-R13-F49-b & 58 & 57 & $514 / 72$ & $346 / 49$ & $247 / 35$ & $365 / 51$ & 413 & Delamination \\
\hline 3 & B-NP-R13-F49-c & 56 & & $514 / 72$ & $346 / 49$ & $247 / 35$ & $365 / 51$ & 399 & Delamination \\
\hline 4 & B-TP-R13-F49-a & 70 & & $514 / 72$ & $346 / 49$ & $247 / 35$ & $365 / 51$ & 500 & Delamination \\
\hline 5 & B-TP-R13-F49-b & 64 & 67 & $514 / 72$ & $346 / 49$ & $247 / 35$ & $365 / 51$ & 457 & Delamination \\
\hline 6 & B-TP-R13-F49-c & 66 & & $514 / 72$ & $346 / 49$ & $247 / 35$ & $365 / 51$ & 471 & Delamination \\
\hline 7 & B-TLP-R13-F49-a & 82 & & $514 / 72$ & $346 / 49$ & $247 / 35$ & $365 / 51$ & 588 & Anchor rupture \\
\hline 8 & B-TLP-R13-F49-b & 91 & 85 & $514 / 72$ & $346 / 49$ & $247 / 35$ & $365 / 51$ & 654 & Anchor rupture \\
\hline 9 & B-TLP-R13-F49-c & 83 & & $514 / 72$ & $346 / 49$ & $247 / 35$ & $365 / 51$ & 595 & Sheets fracture \\
\hline 10 & B-TLP-R0-F49-a & 74 & & $444 / 62$ & $296 / 42$ & $197 / 28$ & $305 / 43$ & 529 & Delamination \\
\hline 11 & B-TLP-R0-F49-b & 90 & 79 & $444 / 62$ & $296 / 42$ & $197 / 28$ & $305 / 43$ & 647 & Delamination \\
\hline 12 & B-TLP-R0-F49-c & 73 & & $444 / 62$ & $296 / 42$ & $197 / 28$ & $305 / 43$ & 522 & Delamination \\
\hline 13 & U-TLP-R13-F49-a & 76 & 74 & $514 / 72$ & $346 / 49$ & $247 / 35$ & $365 / 51$ & 544 & Delamination \\
\hline 14 & U-TLP-R13-F49-b & 78 & 14 & $514 / 72$ & $346 / 49$ & $247 / 35$ & $365 / 51$ & 558 & Delamination \\
\hline 15 & U-TLP-R13-F49-c & 69 & & $514 / 72$ & $346 / 49$ & $247 / 35$ & $365 / 51$ & 493 & Delamination \\
\hline 16 & B-TLP-R0-F37-a & 101 & & $444 / 62$ & $296 / 42$ & $197 / 28$ & $305 / 43$ & 729 & Sheets fracture \\
\hline 17 & B-TLP-R0-F37-b & 95 & 95 & $444 / 62$ & $296 / 42$ & $197 / 28$ & $305 / 43$ & 684 & Sheets fracture \\
\hline 18 & B-TLP-R0-F37-c & 90 & & $444 / 62$ & $296 / 42$ & $197 / 28$ & $305 / 43$ & 647 & Sheets fracture \\
\hline 19 & U-TLP-R13-F37-a & 85 & & $514 / 72$ & $346 / 49$ & $247 / 35$ & $365 / 51$ & 610 & Sheets fracture \\
\hline 20 & U-TLP-R13-F37-b & 71 & 87 & $514 / 72$ & $346 / 49$ & $247 / 35$ & $365 / 51$ & 507 & Concrete peel off \\
\hline 21 & U-TLP-R13-F37-c & 105 & & $514 / 72$ & $346 / 49$ & $247 / 35$ & $365 / 51$ & 760 & Sheets fracture \\
\hline
\end{tabular}

